\section{Acknowledgements}

We thank Dr I. Pullen and the staff of the Medical Records Department for their help in this study.

\section{References}

Blaney, D. \& WeSt, A. (1987) Out of hours referrals to a General Psychiatric Hospital. Health Bulletin (Scotland), 45, 67-70.

Department of Health (1989) Caring for People: Community Care in the Next Decade and Beyond. London: HMSO.
Haw, C., Lanceley, C. \& Vickers, S. (1987) Patients at a psychiatric walk-in clinic-who, how, why and when? Bulletin of the Royal College of Psychiatrists, 11, 329332.

Johnstone, E. C., Crow, T. J., Johnson, A. L. \& MacMillan, J. F. (1986) The Northwick Park Study of first episodes of schizophrenia - presentation of the illness and problems relating to admission. British Journal of Psychiatry, 148, 115-119.

LiM, M. H. (1983). A psychiatric emergency clinic: a study of attendances over six months. British Journal of Psychiatry, 143, 460-466.

\title{
What would Adolf Meyer have thought of the neo-Kraepelinian approach?
}

\author{
D. B. Double, Lecturer in Psychiatry, University Department of Psychiatry, \\ Northern General Hospital, Sheffield S5 7AU
}

Because of the problem of diagnostic unreliability in psychiatry, there has been a trend over recent years to create explicit diagnostic criteria, such as the Research Diagnostic Criteria and DSM-III. This movement has been called neo-Kraepelinian (Klerman, 1978) as it promotes many of the ideas associated with the views of Kraepelin, regarded as the founder of modern psychiatry. It favours a biological approach and arose partially as a response to attacks on the 'medical model' in psychiatry.

Adolf Meyer (1866-1950) is remembered for his opposition to the preoccupation of the Kraepelinians with diagnosis. Although he accepted that there may be a place for classification, he argued that if diagnosis was meaningful, it was secondary to the assessment of the patient as a person. He was regarded as extremely influential in American psychiatry in the first half of this century, but his influence at the Phipps clinic, where he was the first director from when it opened in 1913, had faded by the mid-1950s when visited by Shepherd (1986) and, in general, little is now known about his contribution to psychiatry. A typical evaluation of his approach has been that it was "almost entirely sterile" (Slater \& Roth, 1969).

Whereas Meyer's writings are complex and turgid to read, there has been a clear-cut statement of the neo-Kraepelinian position. Klerman (1978) suggests there are nine assumptions which form the basis of the movement. Each of these propositions is listed below and examined hypothetically from Meyer's viewpoint. Because of Meyer's rejection of many of Kraepelin's views, it is reasonable to expect that he would have regarded the more modern approach as a similar escape from the uncertainties of psychiatry. It is probably because of his personal style that his contributions are now largely forgotten, perhaps in a similar way to Aubrey Lewis, who studied under Meyer, and whose legacy was negatively reviewed by Stengel (1968) among others. Such a tradition, though, should have more to offer to the current 
psychiatric scene and a re-evaluation of Meyer's views about mental disorder may, in fact, be productive.

\section{(1) "Psychiatry is a branch of medicine"}

Meyer regarded 'the 'person' as the essential setting for all medical thought" (Meyer, 1951, III, 497). He criticised medical training for inadequate recognition of the importance of the doctor-patient relationship in general medicine as well as psychiatry. "As soon as the rest of medical training recognises its obligation to pay reasonable attention to the person and to personality-function as part of all physicianpatient relationship, it will be possible to consider an internship in one of the general medical branches an important part of the foundation for psychiatric graduate training" (Meyer, 1951, III, 80).

In practice, Meyer can be seen as distancing psychiatry from medicine. He refused to admit cases of general paresis because he regarded them as essentially medical problems. Although he maintained his interest in neuroanatomy, considerations of neuroanatomy or neuropathology practically never arose in case conferences. He regarded the advent of insulin shock therapy as a resurgence of medical emphasis where humane psychological interest should have prevailed.

\section{(2) "Psychiatry should utilise modern scientific methodologies and base its practice on scientific knowledge"}

Meyer took over the Huxleyan notion of science as "being organised commonsense" (Meyer, 1951, III, 88). He aimed to bring the study of the person into science and believed that the psychiatrist "deals with a wide range of facts usually left to untrained commonsense, but now available as a more and more organised body of facts, methods of study and methods of therapeutic procedure" (Meyer, 1951, III, 44). He recognised that such an approach could be "scoffed at because it looked as if one was not dealing with dependable and effective data" (Meyer, 1952 , IV, 4), and hoped that the argument that "since science has only a physical basis, it cannot be applied to mental life" (Meyer, 1951, II, 573) would become archaic.

\section{(3) "Psychiatry treats people who are sick and who require treatment for mental illness"}

Meyer did not make "an absolute distinction between mental disorders to be dealt with by the teacher and moralist, and the disorders which must be left to the physician" (Meyer, 1952, IV, 173). He can be seen as creating a wide sphere for psychiatric treatment and influence. Mental illness should be discussed not in terms "of mysterious events" (Meyer,
1951, II, 586). Patients are sick "by actually living in ways which put their mind and the entire organism and its activity in jeopardy" (Meyer, 1952, IV, 4).

(4) "There is a boundary between the normal and the sick"

Meyer was opposed to the idea that a hypothetical underlying lesion should be postulated just because some mental disorders may seem unintelligible. He favoured a psychogenetic explanation of mental illness and regarded it as not so completely foreign to normal experience. In particular, he explained schizophrenia (dementia praecox) as a maladaptation that could be understood in terms of the patient's life experiences. He found "in many a case of dementia praecox far more forerunners of actual mischief than the average alienist gets at by his examination when he avoids the facts or does not know how to use them" (Meyer, 1951, II, 583). He argued that the schizophrenic development was "far from being inconceivable as chains of faulty mental adjustment and far from demanding artificial explanations by specially invented poisons and a clamouring for invented 'things back of it all"' (Meyer, 1951, II, 450).

(5) "There are discrete mental illnesses. Mental illnesses are not myths. There is not one, but many mental illnesses. It is the task of scientific psychiatry, as of other medical specialities, to investigate the causes, diagnosis, and treatment of these mental illnesses"

Meyer proposed a system of reaction-types which were not diagnoses but a structural analysis of abnormal responses of "frequently recurring acquaintances" (Meyer, 1951, II, 662). The various reaction types were not seen as necessarily exclusive of each other in one patient and there could be combinations.

The neo-Kraepelinians may have been particularly scathing of the views of writers like Szasz who insist that mental disorders are not illnesses. Meyer wrote: "Very often the supposed disease back of it all is a myth and merely a self-protective term for an insufficient knowledge of the conditions of reaction" (Meyer, 1951, II, 585). Meyer's reaction patterns were at one time a hallmark of American psychiatry.

\section{(6) "The focus of psychiatric physicians should be particularly on the biological aspects of mental illness"}

Meyer had a broad biological viewpoint, seeing human biology as to do with the life of man. He argued for brain-mind integration in his concept of psychobiology, avoiding the "doctrine of psychophysical parallelism" (Meyer, 1951, III, 38). He was fond 
of calling a "neurologising tautology" (e.g. Meyer, 1952 , IV, 352) any attempt to reduce accounts of personality to brain diseases. The danger is that modern psychiatry, despite Meyer, has come to focus too much on the brain as an organ and overlooks the experience of the patient as a person.

\section{(7) "There should be an explicit and intentional concern with diagnosis and classification"}

Meyer argued that the first aim of the psychiatrist should be to get at the facts of the case rather than to make a diagnosis and indeed "if the facts do not constitute a diagnosis we must nevertheless act on the facts" (Meyer, 1951, II, 146). He understood the "craving for logical unity" (Meyer, 1951, II, 135) in classification but thought that there were dangers in one-word diagnoses which gave a false impression that matters were known "by a system of rules and deductions from the meaning of the newly defined disease entities, with their prognosis and autotoxic or other origin held out to the believer as sufficiently settled for practical purposes"'(Meyer, 1951, II, 136).

(8) "Diagnostic criteria should be codified, and a legitimate and valued area of research should be to validate such criteria by various techniques. Further, departments of psychiatry in medical schools should teach these criteria and not depreciate them, as has been the case for many years"

Meyer was concerned that "a diagnosis usually does justice to only one part of the facts and is merely a convenience of nomenclature" (Meyer, 1951, II, 435). He may be blamed for helping to create the trend which depreciated the role of diagnosis, although psychoanalysis was strong in academic psychiatry in the post-war period in America and may have also played a role. Meyer's concept of reaction types had an influence on the formation of DSM-I, but the form of descriptions of psychiatric disorders in that document are very different from the codified criteria of DSM-III and not necessarily any more valid.

(9) "In research efforts directed at improving the reliability and validity of diagnosis and classification, statistical techniques should be utilised"

Meyer was conscious of the limitations of statistics and the validity of diagnosis, for Meyer, could only be improved by research into the person. "What a difference between the history of a patient reported and studied by the well-trained psychiatrist of today and the account drawn up by the statistically-minded researcher"' (Meyer, 1952, IV, 6-7).

\section{Comment}

It can be seen that although Meyer would have accepted some of the bases of the neo-Kraepelinian movement, he would have been profoundly critical of its emphasis and assumptions. He was fond of seeing the psychobiological point of view as an advance over the reductionistic views of the past, but the resurgence of the neo-Kraepelinian approach demonstrates the longlasting appeal of materialistic explanations and the corresponding need to keep such claims in check. There is, of course, a different context now from Meyer's time and just as the neoKraepelinian approach can be seen as a reaction to so-called "antipsychiatry" ideas, particularly popular before the introduction of DSM-III, there is a need for a restatement of Meyer's views in a postantipsychiatric age. Klerman (1978) anticipated a neo-Meyerian revival, but it seems to have been slow to be formulated. The modern psychiatrist, maybe, has been more willing to hide behind the absolute definitions of the neo-Kraepelinians, rather than face, as Meyer did, "the relativity of all the factors with which he has to deal in our field" (Meyer, 1951, III, 31).

\section{References}

Klerman, G. L. (1978) The evolution of a scientific nosology. In Schizophrenia: Science and Practice (Ed. J. C. Shershow). Cambridge, Mass: Harvard University Press. MEYER, A. (1951 and 1952) Collected Papers (Four Volumes). (Ed. E. Winters). Baltimore: John Hopkins Press.

SHEPHERD, M. (1986) A representative psychiatrist: the career, contributions and legacies of Sir Aubrey Lewis. Psychological Medicine Monograph Supplement 10.

Slater, E. \& Roth, M. (1969) Clinical Psychiatry Third Edition. London: Bailliere, Tindall \& Cassell.

STENGEL, E. (1968) Book Review Inquiries in Psychiatry and The State of Psychiatry by Sir Aubrey Lewis. British Journal of Psychiatry, 114, 127-129.

(A full list of references is available from the author on request). 